$\xi_{p}$

\title{
Optimization of Velocity Flap Structures in High Sensitivity Macrofluidic Airflow Sensor
}

\author{
Mohamad Dzulhelmy bin Amari ${ }^{1 *}$, Muhamad Saifuddin b. Abdull Shukor ${ }^{2}$, Sukarnur Che Abdullah $^{3}$ \\ ${ }^{1}$ Faculty of Mechanical Engineering, University Technology MARA (UiTM ),40150, Shah Alam, Selangor, Malaysia. \\ ${ }^{2}$ School of Engineering, KDU University College,40150 Shah Alam, Selangor, Malaysia. \\ *Corresponding author E-mail: dzulhelmy.a@kdu.edu.my
}

\begin{abstract}
Automated reaction from the system is most important in fulfilling the requirement of the intelligent control system. Hence, many related studies regarding in developing the hardware of the system such as high sensitivity of the airflow sensor in detecting the changes either in user or the environment. The effect of the fast detection of the sensor through the high sensitivity of the airflow sensor have enable the system to identify and analyze the behavior of the user in higher accuracy compared to conventional system. Within the scope of airflow sensitivity, separation between two parts in the airflow sensor in altering the velocity impact have been inquired in purpose, while a few investigations in relations to determine the pressure contour of the main parts have been explored by application of using Computational Fluid Dynamics (CFD. This simulation is performed in the ANSYS program software. Thus, this study consequently intends to be focus on detection the high sensitivity of the airflow movement by distinguishing the high and low velocity impact. The optimization the airflow sensor in this study based on design parameter also done in order to design and develop a highly sensitive airflow sensor
\end{abstract}

Keywords: Airflow sensor, High velocity flap, Low velocity flap, High sensitivity, Optimization.

\section{Introduction}

Recent advances in sensor development have produced an innovative applications that have been of tremendous value to our national security, healthcare, environmental safety, and energy resource management [1]. Sensor is one of the most important element that help people to connect with environment. Those specific input could be light, heat, motion, velocity, moisture and pressure. A sensor provides a corresponding output that generally in form of signal which can be converted to human readable display or transmitted electronically through a network for analyzing or further processing.

However, the accuracy of the airflow sensor still a problem for the engineer as they was disrupted due to many causes such as the weather, environment, and even the material [2]. Existing sensor nowadays in dynamic motion area haven't achieve in detecting high or low velocity with high sensitivity criteria. Thus, this study will integrate the high and low velocity in this airflow sensor to enhance the sensitivity of the sensor. The main objective for this study to characterize the airflow and optimize the structure without affecting the integrity of the structure during the airflow testing stage. Hence, in depth simulation was done towards the airflow and the model structure. As to design a high sensitivity of airflow sensor for low and high velocity, this study will focus on deflection of material and direction of wind velocity in range (0 to $110 \mathrm{~km} / \mathrm{h}$ ) [3].

Testing and simulation will be very crucial in order to find out either the material can withstand some high and low velocity or pressure. The test and analysis must be done for both components of sensing elements which is high velocity flap and low velocity flap to distinguish between the high and low velocity region. Thus, some improvements in terms of design are required in order to optimize the airflow sensor. In result, the improvement will enhance the performance of the sensor.

\section{Methodology}

The design and simulation of high sensitivity of airflow sensor have been completed by integrating of two main software which are SolidWorks and ANSYS software. Both of the software had specific function where SolidWorks software are more to the design and optimization of the airflow sensor while for ANSYS software basically for simulating the behaviour of air and wind velocity analysis. The methodology that implemented in this research are listed in the following stages:

Stage 1 : Pre-evaluation of original design of airflows sensor

Stage 2 : Improvements of the design

Stage 3 : Evaluate the design by simulation from CFD

analysis

Stage 4 : Select best performance criteria based on evaluated results.

\subsection{Pre-Evaluation Stage}

The airflow sensor structure was designed by using non-thermal principle type [4]. Based on the literature review, the thermal approach is less effective due to the outer environment condition that effect the performance of the sensor particularly the weather climate condition [5]. In this stage, the original airflow sensor were designed in SolidWorks software in the same nominal dimension as shown in Figure 1 and 2. Without any changing or optimization, the sensor then had been imported in the ANSYS software to analyze whether this original design is already in high sensitivity or 
not. The design are divided into 3 component which are high velocity flap, low velocity flap and casing

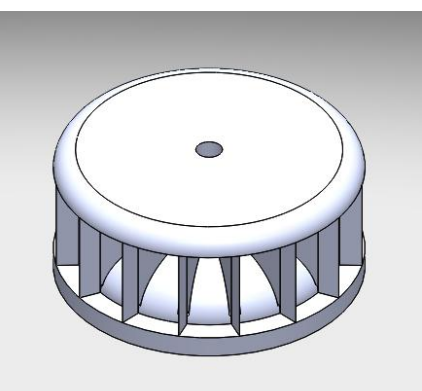

Fig. 1: Airflow sensor structure in SolidWorks 2017

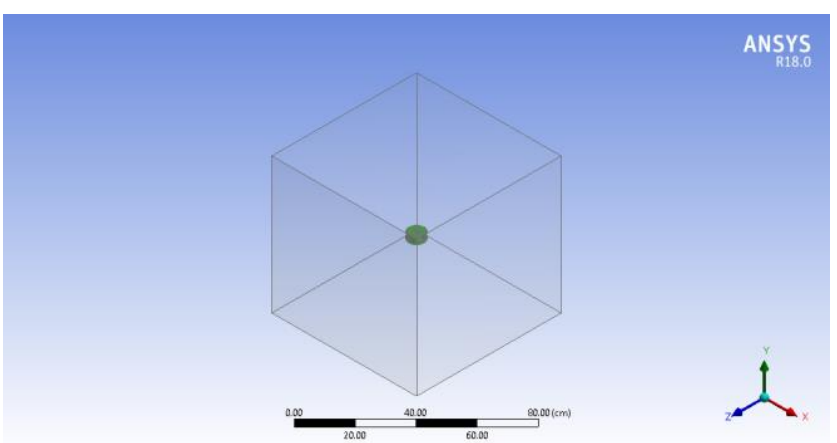

Fig. 2: Imported design of airflow sensor in design modeler of ANSYS software

\subsection{Improvement and Optimization}

In this second stage, improvement in terms of high velocity gap, low velocity gap, high velocity thickness flap and low velocity thickness flap were repeatedly done in order to achieve a suitable thickness and gap as shown in Figure 3, 4 and 5. The material that will be used as the sensor element is PLA plastic (Polyactide) where the maximum yield strength of the material is $70 \mathrm{MPa}$ [6]. By acquiring this value, the analysis structure pressure shouldn't exceed the value of the yield strength to ensure the material will not fail [7].

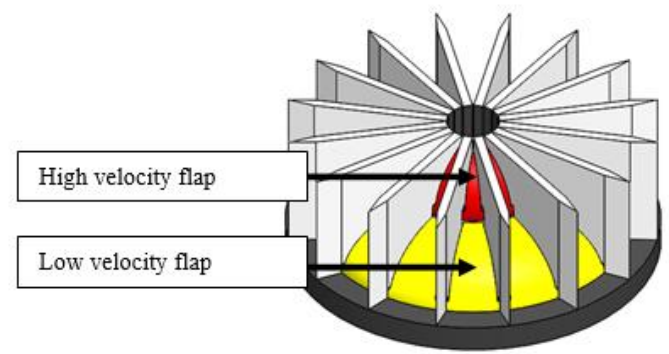

Fig. 3: Design casing of airflow sensor

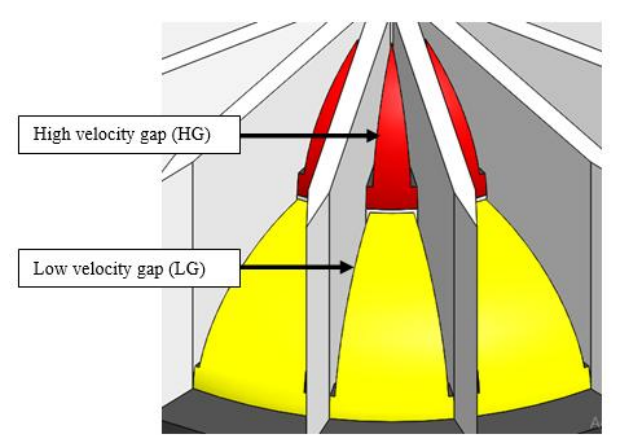

Fig. 4: Close up design of high velocity gap and low velocity gap

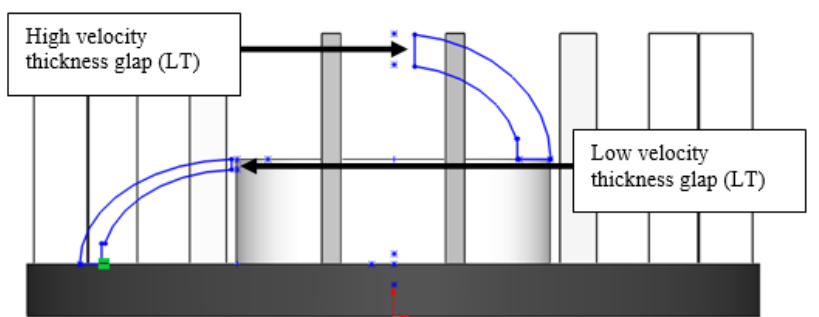

Fig. 5: Sketch of high and low velocity thickness flap

\subsection{Evaluation Stage}

The evaluation stage consists of evaluating and verifying the design that obtained from previous stage. CFD analysis are done in ANSYS software which divided into two section. The first section is analyzing the flow of air velocity in Fluent and validate the static pressure whether the pressure is exceed the yield strength of the material as shown in Figure 6 . The second section in evaluating the deflection of the high and low velocity flap in Static Structural to ensure the sensor can sensitively react to the air velocity as shown in Figure 7.

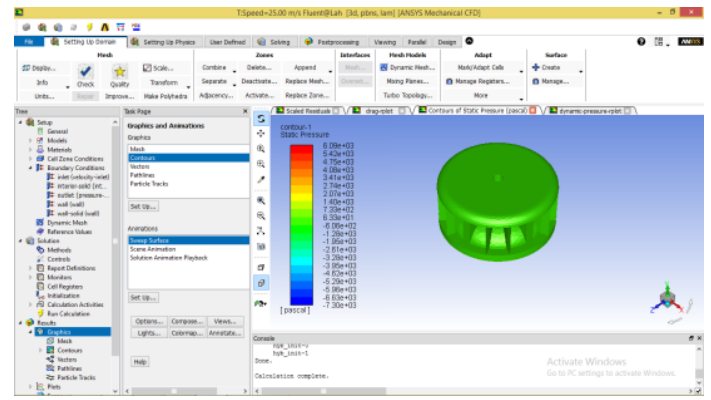

Fig. 6: Screenshot of fluent flow verification of static pressure in Fluent

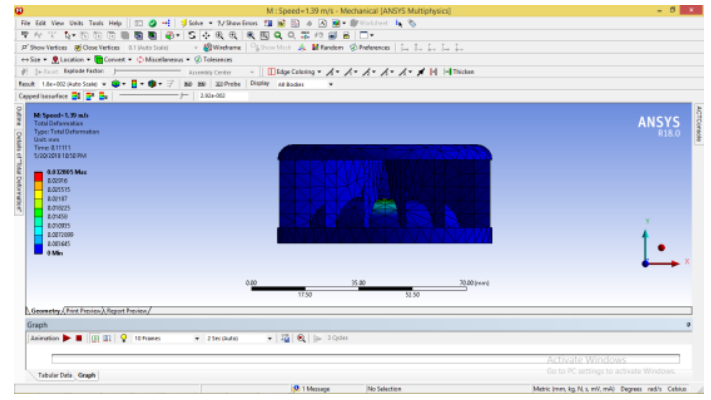

Fig. 7: Screenshot of static structural evaluation to verify the total deformation

\subsection{Performance Selection}

In the last stage, based on the optimization of the design of airflow sensor and evaluation in term of static pressure and deflection of the flap, the best and suitable design had been chosen. This experimental simulation study will be compared in actual situation where it will done in further study. The application that is suitable to be integrated with the sensor is a car. Sensor will be placed at critical point which detect even slightest changes of air movement. The car will be in motion throughout the whole testing to generate accurate result. However, the last stage will be discussed in future paper.

\section{Results and Discussion}

Analysis of the simulations and optimization was starting from analysing the static pressure of original design. The optimization of design were done repeatedly to make sure the airflow sensor can achieve the suitable sizing and thickness. 


\subsection{Pressure Characterization}

The optimization for the flap structure is very important in order to obtain more accurate result. Hence, the simulation parameter and outcome have been focused for the air pressure result surround the structure of the airflow model.

Table 1: The characterization of pressure based on low and high velocity gap as variable at $30.67 \mathrm{~m} / \mathrm{s}$

\begin{tabular}{|c|c|c|c|c|c|c|}
\hline \multirow[t]{2}{*}{ No } & $\begin{array}{c}\text { Lower, } \\
\text { LG } \\
(\mathbf{m m})\end{array}$ & $\begin{array}{c}\text { High, } \\
\text { HG } \\
(\mathbf{m m})\end{array}$ & $\begin{array}{c}\text { Lower } \\
\text { Flap, } \\
\text { LT } \\
(\mathbf{m m})\end{array}$ & $\begin{array}{c}\text { High } \\
\text { Flap, } \\
\text { HT } \\
(\mathbf{m m})\end{array}$ & \multirow[t]{2}{*}{$\begin{array}{l}\text { Pressure } \\
\text { (Pa) }\end{array}$} & \multirow[t]{2}{*}{$\begin{array}{c}\text { Yield } \\
\text { Strength } \\
\text { (MPa) }\end{array}$} \\
\hline & \multicolumn{2}{|c|}{ Gap } & \multicolumn{2}{|c|}{ Thickness } & & \\
\hline 1 & 0.5 & 0.1 & 1 & 2 & $2.33 e+33$ & 70 \\
\hline 2 & 0.4 & 0.1 & 1 & 2 & $2.72 \mathrm{e}+32$ & 70 \\
\hline 3 & 0.3 & 0.1 & 1 & 2 & $4.05 e+21$ & 70 \\
\hline 4 & 0.2 & 0.1 & 1 & 2 & $1.49 \mathrm{e}+21$ & 70 \\
\hline 5 & 0.1 & 0.1 & 1 & 2 & $5.34 \mathrm{e}+20$ & 70 \\
\hline 6 & 0.5 & 0.2 & 1 & 2 & $2.95 e+16$ & 70 \\
\hline 7 & 0.4 & 0.2 & 1 & 2 & $2.44 e+17$ & 70 \\
\hline 8 & 0.3 & 0.2 & 1 & 2 & $9.02 \mathrm{e}+16$ & 70 \\
\hline 9 & 0.2 & 0.2 & 1 & 2 & $1.47 \mathrm{e}+16$ & 70 \\
\hline 10 & 0.1 & 0.2 & 1 & 2 & $4.52 \mathrm{e}+20$ & 70 \\
\hline 11 & 0.5 & 0.3 & 1 & 2 & $4.56 e+08$ & 70 \\
\hline 12 & 0.4 & 0.3 & 1 & 2 & $3.62 \mathrm{e}+08$ & 70 \\
\hline 13 & 0.3 & 0.3 & 1 & 2 & $2.36 \mathrm{e}+09$ & 70 \\
\hline 14 & 0.2 & 0.3 & 1 & 2 & $5.23 e+14$ & 70 \\
\hline 15 & 0.1 & 0.3 & 1 & 2 & $2.58 \mathrm{e}+21$ & 70 \\
\hline 16 & 0.5 & 0.4 & 1 & 2 & $1.46 \mathrm{e}+11$ & 70 \\
\hline 17 & 0.4 & 0.4 & 1 & 2 & $9.99 \mathrm{e}+07$ & 70 \\
\hline 18 & 0.3 & 0.4 & 1 & 2 & $8.02 \mathrm{e}+18$ & 70 \\
\hline 19 & 0.2 & 0.4 & 1 & 2 & $6.82 \mathrm{e}+13$ & 70 \\
\hline 20 & 0.1 & 0.4 & 1 & 2 & $1.17 \mathrm{e}+19$ & 70 \\
\hline 21 & 0.5 & 0.5 & 1 & 2 & $2.72 \mathrm{e}+08$ & 70 \\
\hline 22 & 0.4 & 0.5 & 1 & 2 & $5.74 \mathrm{e}+02$ & 70 \\
\hline 23 & 0.3 & 0.5 & 1 & 2 & $2.70 \mathrm{e}+11$ & 70 \\
\hline 24 & 0.2 & 0.5 & 1 & 2 & $1.22 \mathrm{e}+21$ & 70 \\
\hline 25 & 0.1 & 0.5 & 1 & 2 & $5.86 \mathrm{e}+32$ & 70 \\
\hline
\end{tabular}

The range for lower velocity gap (LG) and high velocity gap (HG) are in the range of 0.5 to $0.1 \mathrm{~mm}$. As for the lower velocity flap thickness (LT) and high velocity flap, the thickness maintained to the original design are $1 \mathrm{~mm}$ and $2 \mathrm{~mm}$ respectively. From the Table 1 above, the first parameter that has been controlled in this analysis is the gap. The importance of this gap parameter to increase or decrease the surface area of the flap itself. According to Yu-Hsiang Wang in his research about the relationship between sensitivity of the flow sensor and the physical dimension of the cantilever structure (Yu-Hsiang W, 2007), as the increases of width of the cantilever beam will increased the flow rate sensitivity [8]. Based on the statement, this study can be relate which the surface area of the flap must have large area in order to increase the sensitivity of airflow sensor. However, for this airflow sensor, the surface area is depending on the value of the gap. Thus, the suitable gap must be determined in order to achieve better and high sensitivity airflow sensor state. As the table above shown, the value of pressure is $2.33 \mathrm{e}+33 \mathrm{~Pa}$ which is the maximum at $0.5 \mathrm{~mm}$ lower velocity gap and $0.1 \mathrm{~mm}$ high velocity gap. The data indicates the surface area at this gap not suitable for the airflow sensor due to high value of pressure.

Therefore, a repeatedly attempt were done by changing the airflow sensor gap in SolidWorks 2017 software and then the file was imported to the ANSYS software to characterize the pressure. In this study, at 22th attempt were found to causes a suitable gap for both high and low thickness due to the pressure value below the yield strength which is $5.74 \mathrm{e}+02 \mathrm{~Pa}$. These results meets the conditions similar with the findings of other studies, in which the material that used for the airflow sensor is PLA, the maximum yield strength is at $70 \mathrm{MPa}$. Thus, based on stress and strain curve in the literature review, the flap must in elastic region which is before the yield point. Yield point is defined as the point on stress and strain curve where it is indicates the limit of elastic region and the initiation of plastic region. Prior to the yield point, when the force or pressure is removed the flap must back to the original shape. The analysis is set up to $30.67 \mathrm{~m} / \mathrm{s}$ which equivalent to 110 $\mathrm{km} / \mathrm{h}$. In Malaysia, the maximum speed limit that was set by the authorities is $110 \mathrm{~km} / \mathrm{h}$. Hence, explained why this study used this speed as one of the controlled parameter in the analysis.

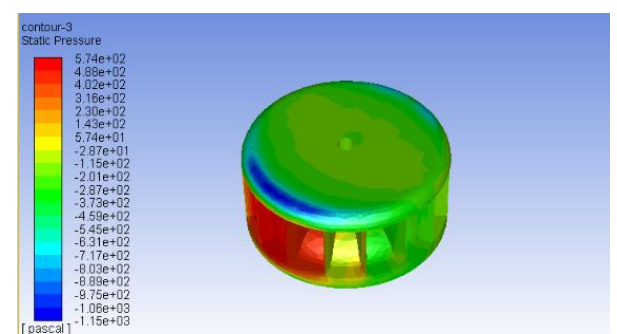

Fig. 8: Static pressure at speed of $30.67 \mathrm{~m} / \mathrm{s}$

The value of static pressure is selected a maximum pressure which is $5.74 \mathrm{e}+02 \mathrm{~Pa}$ as presented in Figure 8. The pressure contour shown a different significant shaded color that indicates the high pressure at the entrance of the model intake. As the static pressure is below the yield strength, the structures still within the elastic region and maintain the high sensitivity region to fulfil the objective of the research.

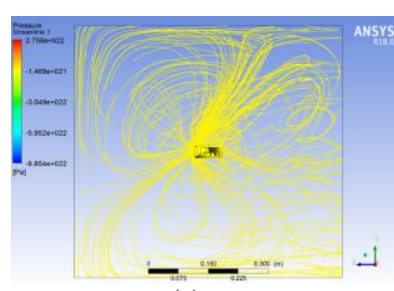

(a)

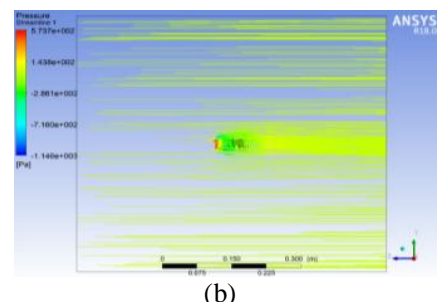

(b)
Fig. 9: Pressure streamline for (a) original design, (b) optimize design

As the Figure 9 shows, there is a significant difference between two design, where clearly show for the original design the flow of air or pressure streamline is too fibrous while for the optimize design the pressure streamline look more smooth and in orderly manner. The result from the original shape structure shows low structure integrity from the unsuitable high and low velocity gap causing the fibrous airflow movement. Besides that, the laminar flow that been set up as a boundary condition becomes turbulence due to the not suitable of gap.

\subsection{Total Deformation}

Total deformation simulation was done to show the integrity of the airflow model structure. This will indicates the maximum bending strength for the structure to sustain in certain speed range.

Table 2: The total deformation of the flap with HT as variable

\begin{tabular}{|c|c|c|c|c|c|c|}
\hline \multirow[t]{2}{*}{ No } & LG & HG & $\begin{array}{c}\text { Lower } \\
\text { Flap, } \\
\text { LT }\end{array}$ & $\begin{array}{c}\text { High } \\
\text { Flap, } \\
\text { HT }\end{array}$ & \multirow[t]{2}{*}{$\begin{array}{l}\text { Pressure } \\
\quad(\mathbf{P a})\end{array}$} & \multirow[t]{2}{*}{$\begin{array}{l}\text { Total Defor- } \\
\text { mation (mm) }\end{array}$} \\
\hline & \multicolumn{2}{|c|}{ Gap (mm) } & \multicolumn{2}{|c|}{ Thickness (mm) } & & \\
\hline 1 & 0.4 & 0.5 & 1 & 2.00 & $5.74 \mathrm{e}+02$ & 0.03203800 \\
\hline 2 & 0.4 & 0.5 & 1 & 2.40 & $2.54 \mathrm{e}+05$ & 0.04591200 \\
\hline 3 & 0.4 & 0.5 & 1 & 2.45 & $5.83 e+02$ & 0.00010346 \\
\hline 4 & 0.4 & 0.5 & 1 & 2.50 & $2.98 \mathrm{e}+06$ & 0.51478000 \\
\hline 5 & 0.4 & 0.5 & 1 & 2.70 & $1.03 \mathrm{e}+05$ & 0.01660700 \\
\hline 6 & 0.4 & 0.5 & 1 & 2.85 & $1.87 \mathrm{e}+03$ & 0.00028494 \\
\hline 7 & 0.4 & 0.5 & 1 & 2.90 & $2.52 \mathrm{e}+03$ & 0.00038004 \\
\hline 8 & 0.4 & 0.5 & 1 & 3.00 & $9.14 \mathrm{e}+03$ & 0.00130940 \\
\hline 9 & 0.4 & 0.5 & 1 & 3.01 & $3.18 \mathrm{e}+06$ & 0.45867000 \\
\hline 10 & 0.4 & 0.5 & 1 & 3.02 & $6.92 \mathrm{e}+07$ & 13.6750000 \\
\hline 11 & 0.4 & 0.5 & 1 & 3.03 & $2.02 \mathrm{e}+07$ & 3.99000000 \\
\hline 12 & 0.4 & 0.5 & 1 & 3.04 & $8.22 \mathrm{e}+04$ & 0.00117130 \\
\hline
\end{tabular}


Table 2 demonstrates the total deformation of the flap in which the high flap velocity thickness (HT) as the controlled parameter From the characterization of pressure result before, this study already verify the suitable gap that can increase the sensitivity of the airflow sensor. The results show that the pressure at $0.4 \mathrm{~mm}$ high velocity gap and $0.5 \mathrm{~mm}$ lower velocity gap is $5.74 \mathrm{e}+02 \mathrm{~Pa}$. The pressure still need to be increase to maximum in achieving the highest sensitivity and perfomance of the airflow sensor. Thus, some improvements have been done and more focus on high flap thickness next controlled parameter.

From data in Table 2, the lower velocity flap thickness (LT), lower (LG) and high velocity gap (HG) will remains constant which is $0.4 \mathrm{~mm}, 0.5 \mathrm{~mm}$ and $1 \mathrm{~mm}$ respectively. As shown in the result above, the range thickness of high velocity flap (HT) is between $2.00 \mathrm{~mm}$ and $3.04 \mathrm{~mm}$. The best possible thickness that give high total deformation is at the thickness of $3.02 \mathrm{~mm}$ which is the total deformation $13.675 \mathrm{~mm}$. In this state, the pressure also indicates at the maximum value which is $69.2 \mathrm{MPa}$. However, the pressure value obtained was still under the yield strength value where the structure under the elastic region.

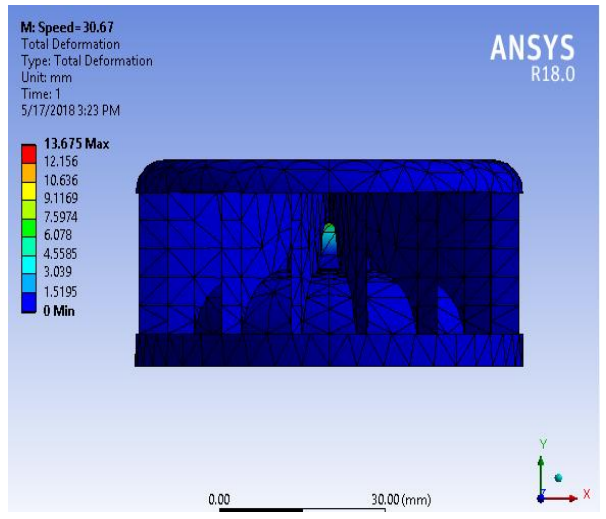

Fig. 10: Static structural shows that the total deformation of high velocity flap at maximum speed of $30.67 \mathrm{~m} / \mathrm{s}$

By integrating in the data obtained in optimization design into static structural analysis, analyzation for the total deflection or deformation can be achieved as shown in Figure 10. The design which has been optimize in terms of gap in previous analysis and the pressure that already verified below the value of yield strength at stage of pressure characterization supposedly to be chosen as a good design. For this analysis, the concept of high sensitivity involved must be considered. Hence, the optimization in terms of thickness also will be done to increase and enchance the perfomance of the sensor.

\subsection{Speed Variable}

As stated in the introduction section, one of the key parameter that need to be covered is speed range. Hence, two separate structure has been designed. In depth simulation has been done to characterize the speed range for both of the structure in capable to detect the airflow changes

Table 3: High speed region indicates value of pressure and total deformation

\begin{tabular}{|l|l|l|l|l|}
\hline No & $\begin{array}{l}\text { Speed } \\
(\mathrm{km} / \mathrm{h})\end{array}$ & $\begin{array}{l}\text { Speed } \\
(\mathrm{m} / \mathrm{s})\end{array}$ & Pressure $(\mathrm{Pa})$ & $\begin{array}{l}\text { Total } \\
\text { Deformation }(\mathrm{mm})\end{array}$ \\
\hline 1 & 40 & 11.11 & $7.99 \mathrm{e}+06$ & 1.5790 \\
\hline 2 & 50 & 13.89 & $16.0 \mathrm{e}+06$ & 3.1619 \\
\hline 3 & 60 & 16.67 & $19.8 \mathrm{e}+06$ & 3.9129 \\
\hline 4 & 70 & 19.44 & $29.7 \mathrm{e}+06$ & 5.8694 \\
\hline 5 & 80 & 22.22 & $32.7 \mathrm{e}+06$ & 6.4622 \\
\hline 6 & 90 & 25.00 & $36.4 \mathrm{e}+06$ & 7.1934 \\
\hline 7 & 100 & 27.78 & $48.1 \mathrm{e}+06$ & 9.5056 \\
\hline 8 & 110 & 30.67 & $69.2 \mathrm{e}+06$ & 13.675 \\
\hline
\end{tabular}

Table 4: Low speed region indicates value of pressure and total deformation

\begin{tabular}{|l|l|l|l|l|}
\hline No & $\begin{array}{l}\text { Speed } \\
(\mathrm{km} / \mathrm{h})\end{array}$ & $\begin{array}{l}\text { Speed } \\
(\mathrm{m} / \mathrm{s})\end{array}$ & Pressure $(\mathrm{Pa})$ & $\begin{array}{l}\text { Total } \\
\text { Deformation }(\mathrm{mm})\end{array}$ \\
\hline 1 & 1 & 0.28 & $1.28 \mathrm{e}+03$ & 0.00448 \\
\hline 2 & 5 & 1.39 & $9.31 \mathrm{e}+03$ & 0.03256 \\
\hline 3 & 10 & 2.78 & $3.37 \mathrm{e}+04$ & 0.11785 \\
\hline 4 & 15 & 4.17 & $0.68 \mathrm{e}+06$ & 2.378 \\
\hline 5 & 20 & 5.56 & $1.16 \mathrm{e}+06$ & 4.0565 \\
\hline 6 & 30 & 8.33 & $5.79 \mathrm{e}+06$ & 20.073 \\
\hline
\end{tabular}

The objective of this study is to detect high sensitity of airflow movement by distinguished high and low velocity region in the sensor model. Therefore, Table 3 indicates the higher region speed which is in the range of $11.11 \mathrm{~m} / \mathrm{s}$ to $30.67(40 \mathrm{~km} / \mathrm{h}$ to $110 \mathrm{~km} / \mathrm{h})$. Based on the optimized design of airflow sensor, the value of pressure and total deformation is specified from the speed controlled parameter. As the result show, the speed of wind or air velocity proportional to the value of pressure and the total deformation. For the high speed region, the maximum speed $30.67 \mathrm{~m} / \mathrm{s}$ which resulting the pressure of $69.2 \mathrm{MPa}$ and the total deformation of $13.675 \mathrm{~mm}$ while for the minimum speed is at $11.11 \mathrm{~m} / \mathrm{s}$ shows the pressure of $7.99 \mathrm{MPa}$ and $1.579 \mathrm{~mm}$ of total deformation. If the value of speed is below the high speed region, this will decrease the pressure and also the total deformation. As the design of high velocity flap is thicker than low flap velocity, the structure will be less effective in detecting slower air flow movement. Thus, the value of total deformation will decrease.

Apart from that, to cover the speed that lower than high speed region, the lower speed region is more effective in order to detect low velocity of air flow movement. Table 4 shows that the lower region speed is in the range of $0.28 \mathrm{~m} / \mathrm{s}$ to $8.33 \mathrm{~m} / \mathrm{s}(1 \mathrm{~km} / \mathrm{h}$ to 30 $\mathrm{km} / \mathrm{h}$ ). At this region, the maximum speed produced pressure is $5.79 \mathrm{MPa}$ and the total deformation of flap is $20.073 \mathrm{~mm}$. While for speed $0.28 \mathrm{~m} / \mathrm{s}, 1.39 \mathrm{~m} / \mathrm{s}$ and $2.78 \mathrm{~m} / \mathrm{s}$ show that the total deformation is quite small which is below than $1 \mathrm{~mm}$. The future improvements must be done in order to increase the perfomance and sensitivity of the airflow sensor by optimizing the angle of attack of the flap.

\section{Conclusion}

The research that have been conducted may conclude that significant value of deflection obtained to distinguish between high and low velocity region. The characterization of the parameter set in the analysis will be very important data that can be used for verification in actual experimentation for the prototype stage.

\section{Acknowledgement}

This research was financially supported by the Geran Inisiatif Penyelidikan (600-IRMI/MyRA 5/3/GIP (012/2017), Universiti Teknologi MARA, Malaysia.

\section{References}

[1] I. F. Akyildiz, W. Su, Y. Sankarasubramaniam, and E. Cayirci (2002), "A survey on sensor networks," IEEE Commun. Mag., vol. 40 , no. 8 , pp. $102-105$

[2] M. J. Zulhaidi, S. Rohayu, W. S. Voon, and S. Ahmad Farhan, (2009), Weather as a road safety hazard in Malaysia-an overview.

[3] K. A. Ishak, M. M. Sani, N. M. Tahir, S. A. Samad, and A. Hussain (2006), “A Speed limit Sign Recognition System Using Artificial Neural Network," 2006 4th Student Conf. Res. Dev., no. SCOReD, pp. 127-131.

[4] N. Svedin, E. Kälvesten, and G. Stemme (2003), "A lift force sensor with integrated hot-chips for wide range flow measurements," Sensors Actuators, A Phys., vol. 109, no. 1-2, pp. $120-130$.

[5] F. Application, P. Data, A. K. Cheung, L. W. Henderson, and P. E. 
Sever (1990), "United States Patent [19]," vol. M, no. 5

[6] J. Torres, J. Cotelo, J. Karl, and A. P. Gordon (2015) "Mechanical property optimization of FDM PLA in shear with multiple objectives," Jom, vol. 67, no. 5, pp. 1183-1193.

[7] D. Y. W. Yu and F. Spaepen (2004) "The yield strength of thin copper films on Kapton," J. Appl. Phys., vol. 95, no. 6, pp. 29912997.

[8] Y. H. Wang, C. Y. Lee, and C. M. Chiang (2007) "A MEMS-based air flow sensor with a free-standing microcantilever structure," Sensors, vol. 7, no. 10, pp. 2389-2401. 